\title{
A furin inhibitor downregulates osteosarcoma cell migration by downregulating the expression levels of MT1-MMP via the Wnt signaling pathway
}

\author{
BINGSHAN LIU, GUOJUN LI, XIAO WANG and YANG LIU \\ Department of Orthopaedics, Huaihe Hospital, Henan University, Kaifeng, Henan 475001, P.R. China
}

Received June 24, 2013; Accepted December 20, 2013

DOI: $10.3892 / \mathrm{ol} .2014 .1839$

\begin{abstract}
This study aimed to explore the exact mechanism of the effect of a furin inhibitor on the migration and invasion of MG-63 and Saos-2 osteosarcoma cells. MG-63 and Saos-2 osteosarcoma cells were treated with regular culture medium in the presence or absence of $480 \mathrm{nM} \alpha 1$-antitrypsin Portland ( $\alpha 1-P D X)$. Wound-healing and Transwell assays were used for the detection of the effects of $\alpha 1-P D X$ on MG-63 and Saos-2 osteosarcoma cell migration and invasion. Western blot analysis and reverse transcription-polymerase chain reaction were performed to detect the expression levels of membrane type I matrix metalloproteinase (MT1-MMP), Wnt and $\beta$-catenin. A chromatin immunoprecipitation assay was used for detection of the levels of MT1-MMP gene transcription activity. The results showed that $\alpha 1$-PDX treatment significantly reduced the migration and invasion ability of the cells. Notably, the expression levels of MT1-MMP decreased evidently upon $\alpha 1-$ PDX treatment, paralleled with reductions in the expression levels of Wnt and $\beta$-catenin. Further analysis of the transcriptional activity of MT1-MMP revealed that the $\alpha 1$-PDX-induced downregulation of the levels of MT1-MMP was mediated by the Wnt signaling pathway. These data suggest that $\alpha 1-P D X$ plays a vital role in inhibiting MG-63 and Saos-2 osteosarcoma cell migration and invasion by downregulating the expression levels of MT1-MMP via the Wnt signaling pathway.
\end{abstract}

\section{Introduction}

Furin is the best-characterized representative of the mammalian subtilisin-like family of proprotein convertases. It is synthesized as an inactive proenzyme and is rapidly matured by autocatalytic cleavage between the prodomain and the catalytic domain in the endoplasmic reticulum (ER) $(1,2)$. Following

Correspondence to: Professor Guojun Li, Department of Orthopaedics, Huaihe Hospital, Henan University, 8 West Road, Baogongfu, Kaifeng, Henan 475001, P.R. China

E-mail: yongchao12856@126.com

Key words: $\alpha 1-\mathrm{PDX}$, osteosarcoma MG-63 and Saos-2, migration, MT1-MMP, Wnt, $\beta$-catenin this initial cleavage, the propeptide-furin complex leaves the ER and enters the trans-Golgi network (TGN) for its second cleavage $(3,4)$. Thus, furin becomes active to process substrate molecules in multiple compartments in the TGN/endosomal system (5). Numerous protein precursors, including matrix metalloproteinases (MMPs), hormones, growth factors, serum proteins, receptors and adhesion molecules, have been identified as furin substrates (6-8). Membrane type I (MT1)-MMP proenzyme cleavage by furin is considered to be a principal event in the activation of this substrate and may play a vital role in tumor cell migration (9).

Furin activation plays a vital role in tumor development (10). The furin inhibitor $\alpha 1$-antitrypsin Portland ( $\alpha 1-P D X)$ has been used to block furin activity and to prevent cancer metastasis in biochemical, cellular and animal studies (11).

The Wnt signaling pathway plays a vital role in normal development, but also in tumorigenesis $(12,13)$. Inappropriate activation of the Wnt signaling pathway results in the onset of several types of cancer (14). Based on the different interactions between Wnt receptors or co-receptors, the Wnt signaling pathway is divided into three signaling pathways, namely the canonical Wnt/ $\beta$-catenin signaling pathway, and the non-canonical (or heretical) Wnt/ $\mathrm{Ca}^{2+}$ and planar cell polarity (PCP) signaling pathways (15). Previous studies have suggested that the interaction of the Wnt/PCP signaling pathway with certain key molecules is associated with cancer cell migration and invasion $(16,17)$. The canonical Wnt signaling pathway involves a key mediator, $\beta$-catenin, which is able to enter the cell nucleus and associate with the transcription factors lymphoid enhancer-binding factor 1 and T-cell factor, leading to the transcription of Wnt target genes $(18,19)$. The stabilization of $\beta$-catenin is regulated by phosphorylation modification by glycogen synthase kinase $3 \beta$, followed by degradation via the proteasome. Abnormal activation of the $\mathrm{Wnt} / \beta$-catenin signaling pathway has been detected in a number of types of human tumor, including lung, breast, cervical and liver, and is due to lack of degradation and ultimately the nuclear accumulation of $\beta$-catenin. In patients with hepatocellular carcinoma, $\beta$-catenin accumulation has been linked to poor differentiation and high proliferative activity of cells, and a poor prognosis $(20,21)$. The levels of $\beta$-catenin are regulated by numerous types of protein, which may lead to the onset of cancer if not regulated or expressed appropriately. By forming a complex with transcription factor 4 , $\beta$-catenin activates the transcription of target 
genes, including MT1-MMP, whose expression levels correlate with the levels of cell migration and invasion (22). Abnormal expression of MT1-MMP has been detected in numerous types of cancer. Such induction of the expression of MT1-MMP could be regulated by the $\mathrm{Wnt} / \beta$-catenin signaling pathway; this is based on the observation that depletion of $\beta$-catenin in SW480 colorectal carcinoma cells results in the downregulation of the expression levels of MT1-MMP (23). In a previous study, it was demonstrated that the migration of MG-63 and Saos-2 osteosarcoma cells was inhibited significantly by a certain range of concentrations of $\alpha 1-P D X$ treatment (10), but the exact molecular mechanism of this effect remains unknown.

\section{Materials and methods}

Cell culture and experimental reagents. MG-63 and Saos-2 osteosarcoma cells were purchased from the American Type Culture Collection (Manassas, VA, USA) cultured in RPMI-1640 (Invitrogen Life Technologies, Carlsbad, CA, USA) supplemented with $10 \%$ fetal bovine serum (FBS), $100 \mathrm{U} / \mathrm{ml}$ penicillin and $100 \mu \mathrm{g} / \mathrm{ml}$ streptomycin, in a $5 \% \mathrm{CO}_{2}$ humidified atmosphere at $37^{\circ} \mathrm{C}$. $\alpha 1-\mathrm{PDX}$ (126850-2.5MG; Calbiochem-Merck KGaA, Darmstadt, Germany) was added to the medium at a concentration of $480 \mathrm{nM}$ where indicated. Primary antibodies against Wnt, $\beta$-catenin, MT1-MMP and $\beta$-actin were purchased from Santa Cruz Biotechnology, Inc. (Santa Cruz, CA, USA). Other reagents were used, including anti-mouse-IgG-HRP and anti-rabbit-IgG-HRP (BD Biosciences, CA, USA) and Transwell invasion chambers (Promega, Madison, WI, USA).

Monolayer cell migration assay. A monolayer wound-healing model was performed as a cell migration assay. MG-63 and Saos-2 osteosarcoma cells were seeded in a six-well-plate for $48 \mathrm{~h}$ in complete RPMI-1640 medium. A confluent monolayer of MG-63 and Saos-2 osteosarcoma cells was then scraped with a sterile $200-\mu 1$ pipette tip into another six-well-plate and washed with phosphate-buffered saline (PBS). Following incubation with complete RPMI-1640 or $\alpha 1$-PDX (480 nM) for $48 \mathrm{~h}$, cell migration images were captured using an inverted phase contrast microscope at x100 magnification.

Transwell invasion assay. The Matrigel invasion chambers were hydrated for $4 \mathrm{~h}$ prior to starting the invasion assay. Log-phase cells $\left(4 \times 10^{4}\right)$ were plated in $200 \mu \mathrm{l}$ complete RPMI-1640 containing $10 \%$ FBS in the upper chamber of the Transwell, and the lower chamber was filled with $500 \mu \mathrm{l}$ complete RPMI-1640 containing $10 \%$ FBS. Following incubation for $2 \mathrm{~h}$, the cells were treated with $\alpha 1-P D X$ as decribed previously and allowed to migrate for $10 \mathrm{~h}$ at $37^{\circ} \mathrm{C}$ and $5 \% \mathrm{CO}_{2}$. The cells were fixed for $15 \mathrm{~min}$ at room temperature by replacing the culture medium in the bottom and top of the chamber with $4 \%$ formaldehyde buffer. Subsequently, the chambers were rinsed in PBS and stained with $0.1 \%$ crystal violet for $10 \mathrm{~min}$, then the migrated cells were photographed under an optical microscope. The cell number was counted at 12 different areas. Data were averaged from three parallel experiments, which were normalized to those of the controls.

Reverse transcription-polymerase chain reaction (RT-PCR) analysis. The cells were incubated with $\alpha 1-\mathrm{PDX}$ for $48 \mathrm{~h}$ prior to RT-PCR. Total RNA was extracted from the MG-63 and Saos-2 osteosarcoma cells using the TRIzol method (Invitrogen Life Technologies). RT was performed with $1 \mu \mathrm{g}$ total RNA and $10 \mu \mathrm{M}$ of the specific primers. The cDNAs were amplified by PCR for MT1-MMP (sense, 5'-AGCCCCGAAGCCTGGCTACA-3'; and antisense, 5'-GCCGCCCTCACCATCGAAGG-3'; 492-bp product), or glyceraldehyde 3-phosphate dehydrogenase was used as the endogenous reference housekeeping gene (sense, 5'-ACCACAGTCCATGCCATCAC-3'; and antisense, 5'-TCCACCACCCTGTTGCTGTA-3'; 556-bp product). The PCR conditions were as follows: $95^{\circ} \mathrm{C}$ for $5 \mathrm{~min}$, followed by 30 cycles of $95^{\circ} \mathrm{C}$ for $15 \mathrm{sec}, 60^{\circ} \mathrm{C}$ for $30 \mathrm{sec}$ and $72^{\circ} \mathrm{C}$ for $45 \mathrm{sec}$.

Western blot analysis. The cells were incubated with $\alpha 1-\mathrm{PDX}$ for $48 \mathrm{~h}$ prior to western blotting. MG-63 and Saos-2 osteosarcoma cells were lysed in radioimmunoprecipitation assay (RIPA) buffer (50 mM Tris pH 7.4, $150 \mathrm{mM} \mathrm{NaCl,} 1 \%$ Triton $\mathrm{X}-100,0.1 \%$ SDS, $1 \%$ sodium deoxycholate, $5 \mathrm{mM}$ EDTA, $100 \mathrm{mM} \mathrm{NaF}$, and $1 \mathrm{mM} \mathrm{Na} \mathrm{VO}_{4}$ ) containing a protease inhibitor cocktail (product no., 04693116001; Roche, Madison, WI, USA)for $30 \mathrm{~min}$ on ice, followed by centrifugation for $30 \mathrm{~min}$ at $35,800 \mathrm{x} \mathrm{g}$. The protein concentrations were determined by the bicinchoninic acid assay method (Pierce BCA Protein Assay kit; Pierce Biotechnology, Inc., Rockford, IL, USA). Equal quantities of total proteins were electrophoresed by $12 \%$ SDS-PAGE gel, followed by transfer to polyvinylindene difluoride membranes using a wet transblot system (Bio-Rad, Hercules, CA, USA). The membranes were blocked for $1 \mathrm{~h}$ at room temperature with $5 \%$ nonfat dry milk and incubated overnight at $4^{\circ} \mathrm{C}$ with antibodies [rabbit anti-Wnt, $\beta$-catenin, MT1-MMP and mouse anti- $\beta$-actin $(1: 1,000)]$. After washing, the membranes were incubated for $1 \mathrm{~h}$ with HRP-conjugated goat anti-rabbit or anti-mouse-IgG-HRP secondary antibodies diluted to 1:5,000 in PBS Tween-20. After further washing and processing using SuperSignal West Pico Chemiluminescent substrate (Pierce Biotechnology, Inc.), the membranes were exposed to a Fujifilm LAS-3000 Imager (Fuji, Tokyo, Japan). The band densities of the western blots were normalized relative to the relevant $\beta$-actin band density with ImageJ Analysis software (National Institutes of Health, Bethesda, MD, USA).

Chromatin immunoprecipitation (ChIP) assay. The cells were incubated with $\alpha 1$-PDX for $48 \mathrm{~h}$ prior to performing the ChIP assay. A ChIP assay was performed using a ChIP kit (Sigma-Aldrich, St. Louis, MO, USA) with slight modifications. MG-63 and Saos-2 osteosarcoma cells $\left(2 \times 10^{7}\right)$ were cross-linked with $1 \%$ formaldehyde for $10 \mathrm{~min}$ at room temperature, followed by the addition of $1 \mathrm{ml}$ of $125 \mathrm{mM}$ glycine to inactivate the formaldehyde. The cells were washed twice with ice-cold PBS and then scraped and centrifuged at $1,000 \mathrm{x}$ g at $4^{\circ} \mathrm{C}$ for $5 \mathrm{~min}$. The pelleted cells were lysed with $1 \mathrm{ml}$ modified-RIPA lysis buffer $(0.1 \%$ SDS, 10 mM EDTA, $1 \%$ Triton X-100 and $50 \mathrm{mM}$ Tris- $\mathrm{HCl} \mathrm{pH}$ 8.1) containing a protease inhibitor cocktail and incubated on ice for $10 \mathrm{~min}$. Following sonication to produce genomic DNA with lengths of $0.2-0.5 \mathrm{~kb}$, the samples were centrifuged at $13,000 \times \mathrm{g}$ for $10 \mathrm{~min}$ to remove insoluble cell debris. The lysates were diluted in ChIP dilution buffer $(0.01 \%$ SDS; $1.1 \%$ Triton X-100; 2 mM EDTA; 20 mM Tris-HCl, 

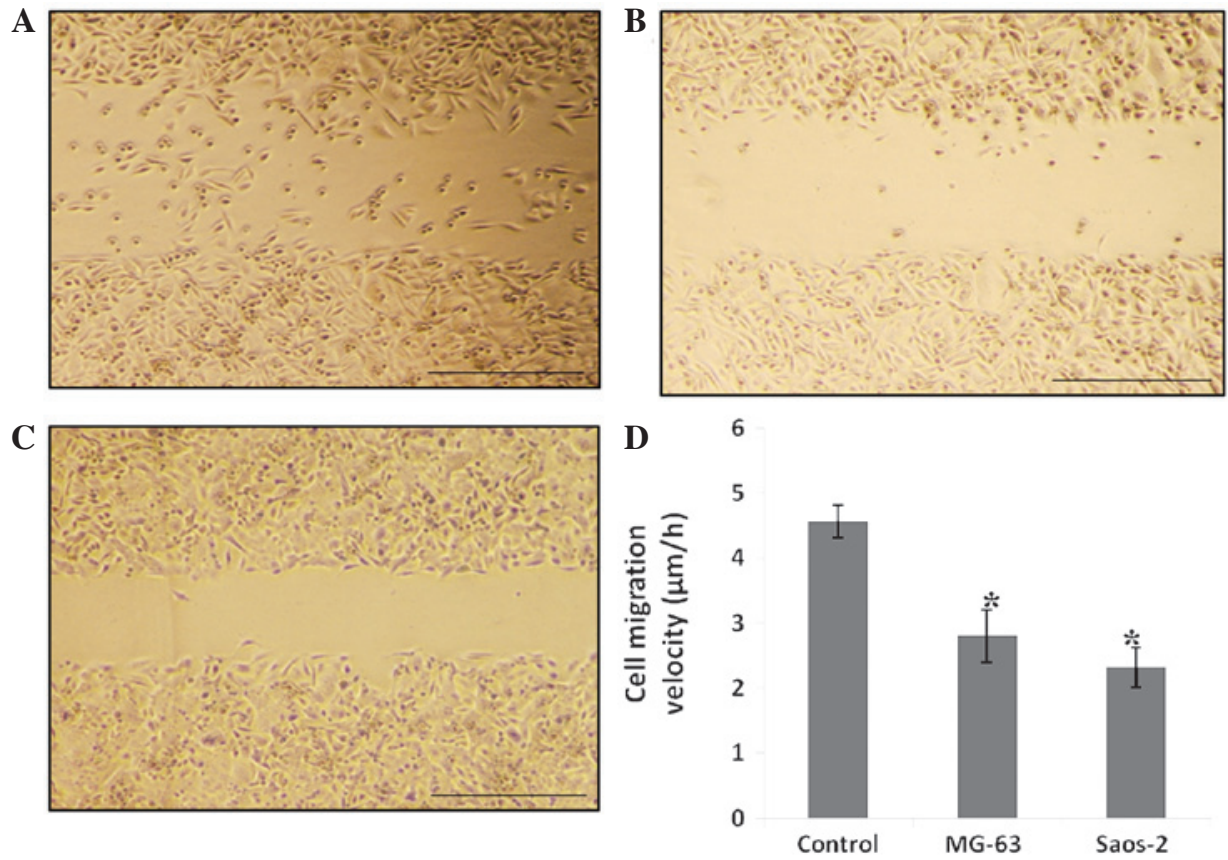

Figure 1. Regulation of cell migration by $\alpha 1$-PDX in osteosarcoma MG-63 and Saos-2 cells. (A) MG-63 log-phase cells treated with normal complete RPMI-1640, and (B) MG-63 and (C) Saos-2 osteosarcoma cells treated with $480 \mathrm{nM} \alpha 1$-PDX. Monolayer cells were scraped with a 200- $\mu 1$ sterile tip. Images of cell migration were captured with an inverted phase contrast microcope (magnification, $\mathrm{x} 20$ )and the migration distance was used for statistical analysis of (D) the cell migration velocity. Data were expressed as the mean cell migration velocity \pm SEM from three separate experiments. Statistical analyses were performed using the t-test and one-way analysis of variance. ${ }^{*} \mathrm{P}<0.05$ indicates a significant difference compared with the control group. $\alpha 1$-PDX, $\alpha 1$-antitrypsin Portland.

$\mathrm{pH} 8.1$; and $500 \mathrm{mM} \mathrm{NaCl}$ ) and protease inhibitor cocktail. Dilutions of the chromatin preparations were stored at $-20^{\circ} \mathrm{C}$. The chromatin solution was precleared with $20 \mu \mathrm{l}$ of $3 \%$ bovine serum albumin/protein A agarose beads for $2 \mathrm{~h}$ at $4^{\circ} \mathrm{C}$ with rotation. Anti- $\beta$-catenin polyclonal antibody (Santa Cruz Biotechnology, Inc.) was added to the precleared supernatant and incubated overnight at $4^{\circ} \mathrm{C}$ with rotation. The negative controls included a sample incubated without antibody and one incubated with rabbit IgG (Santa Cruz Biotechnology, Inc.) to determine whether the interactions were due to nonspecific $\mathrm{IgG}$ interactions. The bead complexes were washed with low-salt immune complex wash buffer (Sigma-Aldrich), followed by high-salt immune complex wash buffer (Sigma-Aldrich) and a final $\mathrm{LiCl}$ immune complex wash buffer (Sigma-Aldrich) for 5 min each on a rotating platform followed by brief centrifugation at $35,800 \mathrm{xg}$ for $10 \mathrm{~min}$. Two final washes in $1 \mathrm{X}$ Tris EDTA buffer were performed for $5 \mathrm{~min}$ each. Following the final wash, the DNA was extracted by incubating the beads twice for 15 min with $200 \mu \mathrm{l}$ freshly prepared elution buffer (1\% SDS and $50 \mathrm{mM} \mathrm{NaHCO}$ ). The samples were then uncrosslinked in a $65^{\circ} \mathrm{C}$ water bath overnight and the DNA was purified using a QIAquick Nucleotide Removal kit (Qiagen Inc., Valencia, CA, USA). The purified DNA was analyzed by PCR. The PCR primers used to amplify the MT1-MMP promoter region were as follows: GTCTCCCGCCCCAAGACCCT (forward) and GGAACACCACATCGGGGGCG (reverse).

Statistical analysis. All experiments were performed three times and the data were expressed as the mean \pm standard error of the mean. Statistical analysis was performed by SPSS software, version 11.0 (SPSS, Inc., Chicago, IL, USA). Differences between the groups were statistically evaluated using the t-test or one-way analysis of variance with post-hoc analysis. $\mathrm{P}<0.05$ was considered to indicate a statistically significant difference.

\section{Results}

Inhibitory effect of $\alpha 1-P D X$ on MG-63 and Saos-2 osteosarcoma cellmigration. The effect of $\alpha 1-P D X$ on MG- 63 and Saos- 2 osteosarcoma cell migration was monitored by a monolayer wound-healing assay. Log-phase cells were seeded on six-well plates and incubated with complete cell medium or $480 \mathrm{nM}$ $\alpha 1$-PDX for $24 \mathrm{~h}$. Following wounding by a sterile $200-\mu \mathrm{l}$ pipette tip, the cells treated with normal cell medium migrated clearly. The cells that were treated with $\alpha 1$-PDX showed no evident migration (Fig. 1). In the three-dimensional cell migration assay with the Transwell system, the cells treated with $\alpha 1$-PDX were found to migrate less than the control cells (Fig. 2). This data indicates that MG-63 and Saos-2 osteosarcoma cell migration was inhibited upon $\alpha 1-P D X$ treatment. However, these assays did not reveal the mechanism of the inhibitory effect.

Downregulation effect of $\alpha 1-P D X$ on the expression levels of MT1-MMP. To explore the possible mechanism of the inhibitory effect of $\alpha 1$-PDX on MG-63 and Saos-2 osteosarcoma cell migration, the expression levels of MT1-MMP, which is the key mediator of cell migration and invasion, were detected. RT-PCR was used for detection of the levels of gene expression of MT1-MMP in MG-63 and Saos-2 osteosarcoma cells upon $\alpha 1$-PDX treatment. From the results (Fig. 3), the gene expression levels of MT1-MMP were reduced significantly in the $\alpha 1-P D X$ treatment cells, compared with those of the control group. The protein levels of MT1-MMP were also detected upon a1-PDX treatment and, as expected, the protein levels also decreased 
A

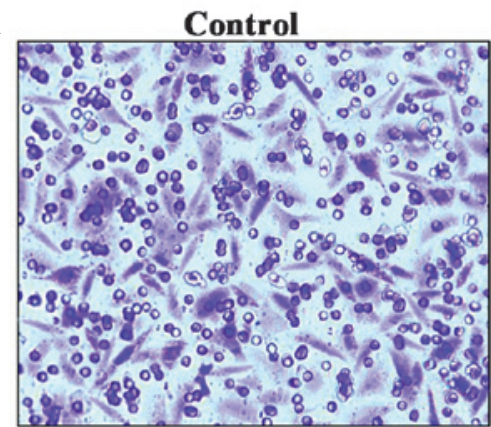

C

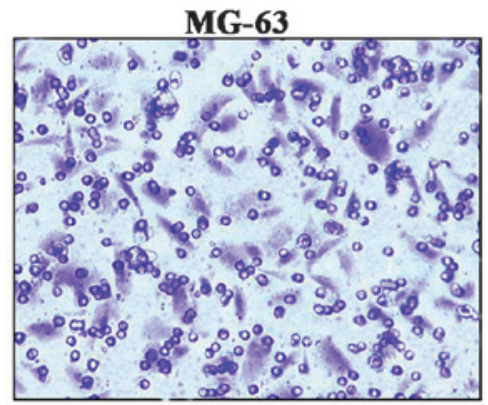

B

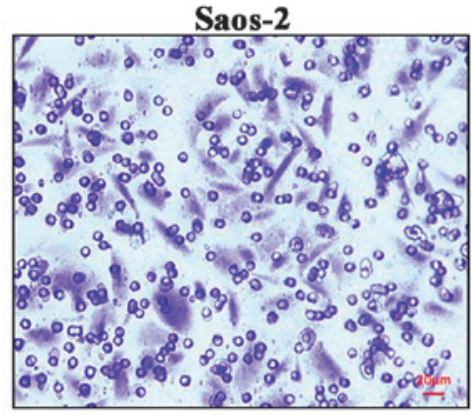

D 120

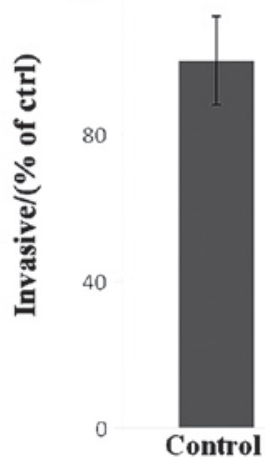

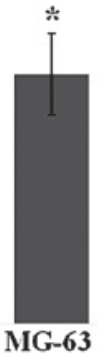

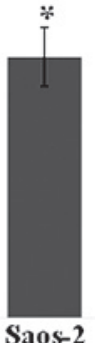

Figure 2. Regulation of invasion by $\alpha 1$-PDX in MG-63 and Saos-2 osteosarcoma cells. The Transwell system was used for detection of the invasion ability of osteosarcoma cells upon $\alpha 1-\mathrm{PDX}$ treatment. (A) MG-63 control cells. (B) Saos-2 and (C) MG-63 osteosarcoma cells were treated with complete RPMI-1640 or $480 \mathrm{nM} \alpha 1-\mathrm{PDX}$, seeded in the upper chamber at a density of $4 \times 10^{4}$ cells per chamber and allowed to migrate through the chamber pore for $12 \mathrm{~h}$. Subsequently, the number of cells per field that had migrated to the bottom surface of the filter was counted. (D) The mean and standard error from three separate experiments are shown. Statistical analyses were performed using the t-test and one-way analysis of variance. ${ }^{*} \mathrm{P}<0.05$ indicates a significant difference compared with the control group. $\alpha 1-P D X, \alpha 1$-antitrypsin Portland.

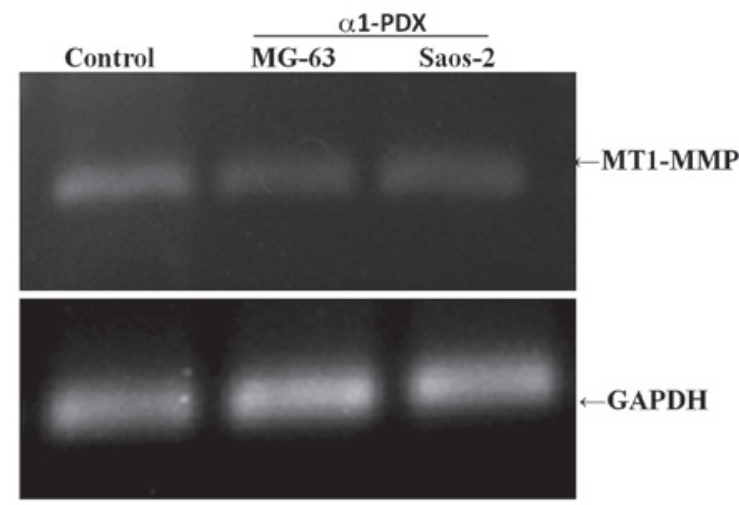

Figure 3. Effect of $\alpha 1$-PDX on the mRNA expression levels of MT1-MMP in MG-63 and Saos-2 osteosarcoma cells. The cells were treated with completed cell culture medium or $480 \mathrm{nM} \alpha 1$-PDX for $48 \mathrm{~h}$ and the mRNA of MT1-MMP was analyzed by reverse transcription-polymerase chain reaction. The mRNA of GAPDH was used for the internal control, which indicated the equal total of mRNA. $\alpha 1$-PDX, $\alpha 1$-antitrypsin Portland; MT1-MMP, membrane type 1-matrix metalloproteinase; GAPDH, glyceraldehyde 3-phosphate dehydrogenase.

evidently compared with those of the control cells (Fig. 4). These results suggest that $\alpha 1$-PDX suppresses MG-63 and Saos-2 osteosarcoma cell migration, possibly via downregulation of the expression of MT1-MMP gene and protein levels.

Wnt signaling pathway may be involved in the downregulation of the levels of MT1-MMP by a1-PDX treatment. To further

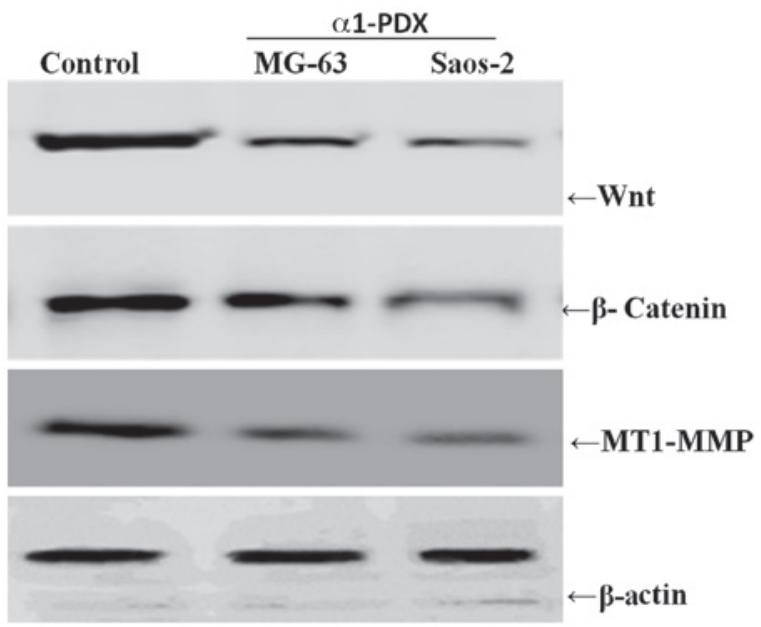

Figure 4. Effect of $\alpha 1$-PDX on the expression levels of MT1-MMP, Wnt and $\beta$-catenin in MG-63 and Saos-2 osteosarcoma cells. The total proteins were extracted from the cells and the expression levels of Wnt, $\beta$-catenin and MT1-MMP were detected with western blot analysis. Equal loading protein was shown with the $\beta$-actin immunoblot. $\alpha 1$-PDX, $\alpha 1$-antitrypsin Portland; MT1-MMP, membrane type 1-matrix metalloproteinase.

explore the exact mechanism by which $\alpha 1-P D X$ downregulates the MT1-MMP expression levels, the effect of $\alpha 1-P D X$ on Wnt signaling pathway-related properties was investigated. When the MG-63 and Saos-2 osteosarcoma cells were treated with $\alpha 1-P D X$ for the indicated times, the expression levels of Wnt and $\beta$-catenin decreased significantly, paralleled with the 


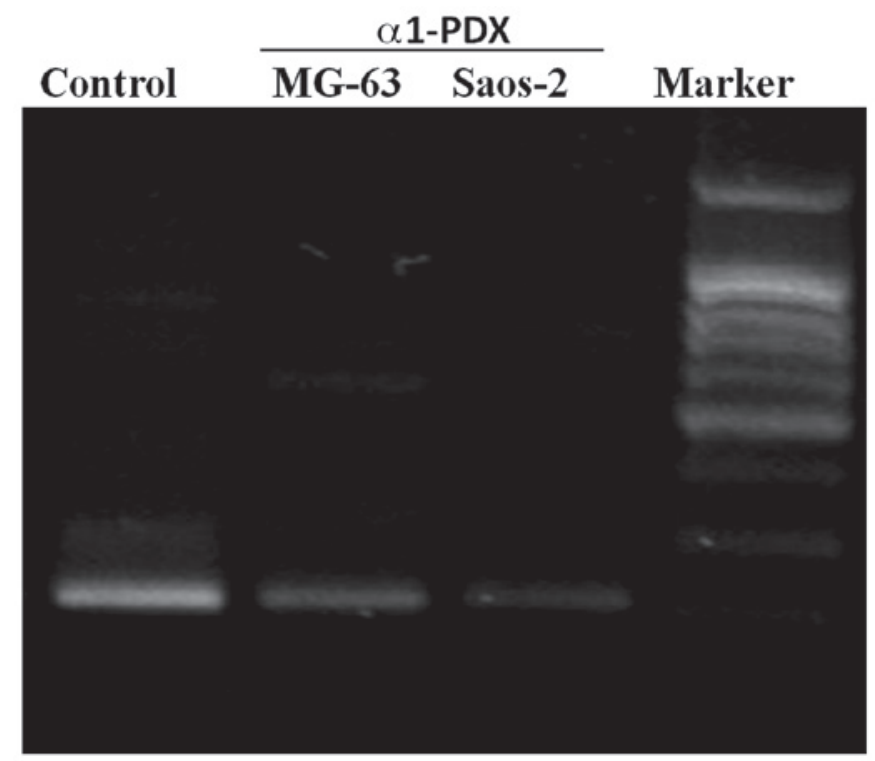

Figure 5. Regulation of $\alpha 1-\mathrm{PDX}$ on the levels of transcriptional activity of MT1-MMP in osteosarcoma MG-63 and Saos-2 cells. The cells were treated as indicated; whole cell lysates were sonicated to produce genome DNA and chromatin samples were immunoprecipitated with $\beta$-catenin antibody, and normal rabbit IgG, then MT1-MMP was amplified by 35 cycles of polymerase chain reaction. $\alpha 1$-PDX, $\alpha 1$-antitrypsin Portland; MT1-MMP, membrane type 1-matrix metalloproteinase.

reduction in the MT1-MMP expression levels (Fig. 4). These results suggested that the downregulating effect of $\alpha 1-P D X$ on the levels of MT-MMP may be via the Wnt signaling pathway.

Effect of $\alpha 1-P D X$ on the levels of MT1-MMP transcriptional activity via the Wnt signaling pathway. To determine whether the levels of MT1-MMP transcriptional activity correlated with the levels of Wnt signaling pathway activity, a ChIP assay was performed. The MG-63 and Saos-2 osteosarcoma cells were treated with $\alpha 1$-PDX for $24 \mathrm{~h}$ and $\beta$-catenin antibody was used for immunoprecipitation with target genes. The results showed that the levels of MT1-MMP transcriptional activity decreased evidently compared with those of the control (Fig. 5), which demonstrated that the effect of $\alpha 1-P D X$ on MT1-MMP expression levels was mediated through Wnt signaling.

\section{Discussion}

Previous studies have indicated that $\alpha 1-P D X$ has the potential role of inhibiting cancer cell migration, but the exact mechanism is unknown. In the present study, it has been demonstrated that $\alpha 1-P D X$ inhibited the migration and invasion of MG-63 and Saos-2 osteosarcoma cells through downregulation of the expression levels of MT1-MMP via the $\mathrm{Wnt} / \beta$-catenin signaling pathway. The invasion ability of osteosarcoma MG-63 and Saos-2 cells upon $\alpha 1-\mathrm{PDX}$ treatment was detected through two- and three-dimensional migration assays (wound-healing and Transwell assays). It was observed that the migration ability was reduced significantly upon $\alpha 1-$ PDX treatment for $24 \mathrm{~h}$. Tumor invasion and metastasis is a multistage and multifactorial process, which is regulated by complicated mechanisms and multiple signaling pathways (24).
Numerous protein molecules are involved in the regulation of cell adhesion, migration and invasion in tumor biology behaviors. MMPs are a family of zinc-binding proteases that have been shown to contribute to cancer cell invasion through the ability to degrade the extracellular matrix $(25,26)$. MT1-MMP (also known as MMP-14) is the first identified and also the most common member of the MT-MMP subfamily involved in pericellular proteolysis associated with cell migration $(27,28)$.

Harada et al and Arii et al have demonstrated that MT1-MMP is involved in hepatocarcinoma cell migration $(29,30)$; however, the molecular mechanism is unknown. In searching for the underlying mechanism of $\alpha 1-P D X$ inhibition of the migration and invasion of MG-63 and Saos-2 osteosarcoma cells in the present study, the expression levels of MT1-MMP mRNA and protein in MG-63 and Saos-2 osteosarcoma cells upon $\alpha 1-\mathrm{PDX}$ treatment were detected. It was identified that the mRNA and protein expression levels of MT1-MMP were decreased evidently upon $\alpha 1-P D X$ treatment.

The activity levels of the majority of MMPs are very low in normal steady state tissues; however, their expression levels are regulated by various inflammatory cytokines, growth factors and hormones, as well as by cell-cell interactions (31). Furthermore, the proteolytic activity of MMPs is strictly controlled at several levels, including transcriptional, post-transcriptional and post-translational, as well as via their endogenous inhibitors $(31,32)$. The transcription of MT1-MMP is strictly regulated by the Wnt signaling pathway $(33,34)$; therefore, we hypothesized that inhibition of MG-63 and Saos-2 osteosarcoma cell migration and invasion by $\alpha 1-\mathrm{PDX}$ may be through downregulation of the Wnt signaling pathway. Based on this assumption, the expression levels of Wnt and $\beta$-catenin were detected in the present study. Western blotting indicated that the expression levels of Wnt and $\beta$-catenin decreased markedly in the $\alpha 1$-PDX-treated cells compared with those of the control; however, the expression levels of the positive control, the docetaxel-treated group, decreased weakly. These results suggested that $\alpha 1$-PDX has a potential role of downregulating the expression levels of Wnt and $\beta$-catenin. To investigate whether the effect of $\alpha 1-P D X$ on the transcriptional activity of MT1-MMP is mediated through the Wnt signaling pathway, the levels of MT1-MMP transcriptional activity were detected through a ChIP assay. As expected, upon $\alpha 1-$ PDX treatment a small level of MT1-MMP was detected, which was decreased significantly compared with that of the control.

In summary, the data of the present study demonstrated that $\alpha 1-P D X$ has the potential role of inhibiting the migration and invasion of MG-63 and Saos-2 osteosarcoma cells, which may be through downregulating the expression levels of MT1-MMP via the canonical Wnt signaling pathway. It is of note that $\alpha 1-P D X$ downregulates the expression levels of transcripts and protein of MT1-MMP, an activator of proMMP-2 (pro-gelatinase A/72 kDa type IV collagenase) (35), which is a major and specific basement membrane matrix protein. Since the degradation of the basement membrane by MMP-2 is likely an essential step for cancer invasion (36-38), it is necessary to study whether $\alpha 1-P D X$ mediates the activity of other MMPs. Therefore, numerous aspects of the mechanism of $\alpha 1-P D X$ remain to be resolved. 


\section{References}

1. Gawlik K, Shiryaev SA and Zhu W: Autocatalytic activation of the furin zymogen requires removal of the emerging enzyme's $\mathrm{N}$-terminus from the active site. PLoS One 4: e5031, 2009.

2. Vey M, Schäfer W, Berghöfer S, Klenk HD and Garten W: Maturation of the trans-Golgi network protease furin: compartmentalization of propeptide removal, substrate cleavage, and COOH-terminal truncation. J Cell Biol 127: 1829-1842, 1994.

3. Creemers JW, Vey M, Schäfer W, Ayoubi TA, Roebroek AJ, Klenk HD, Garten W and Van de Ven WJ: Endoproteolytic cleavage of its propeptide is a prerequisite for efficient transport of furin out of the endoplasmic reticulum. J Biol Chem 270: 2695-2702, 1995.

4. Anderson ED, VanSlyke JK, Thulin CD, Jean F and Thomas G: Activation of the furin endoprotease is a multiple-step process: requirements for acidification and internal propeptide cleavage. EMBO J 16: 1508-1518, 1997.

5. Molloy SS, Thomas L, VanSlyke JK, et al: Intracellular trafficking and activation of the furin proprotein convertase: localization to the TGN and recycling from the cell surface. EMBO J 13: 18-33, 1994

6. Fujisawa T, Kamimura H, Hosaka M, et al: Functional localization of proprotein-convertase furin and its substrate TGFbeta in EGF receptor-expressing gastric chief cells. Growth Factors 22: 51-59, 2004.

7. Louagie E, Taylor NA, Flamez D, et al: Role of furin in granular acidification in the endocrine pancreas: identification of the V-ATPase subunit Ac45 as a candidate substrate. Proc Natl Acad Sci USA 105: 12319-12324, 2008.

8. Yana I and Weiss SJ: Regulation of membrane type-1 matrix metalloproteinase activation by proprotein convertases. Mol Biol Cell 11: 2387-2401, 2000.

9. Dangi-Garimella S, Krantz SB, Barron MR, et al: Three-dimensional collagen I promotes gemcitabine resistance in pancreatic cancer through MT1-MMP-mediated expression of HMGA2. Cancer Res 71: 1019-1028, 2011.

10. López de Cicco R, Bassi DE, Zucker S, et al: Human carcinoma cell growth and invasiveness is impaired by the propeptide of the ubiquitous proprotein convertase furin. Cancer Res 65 : 4162-4171, 2005

11. Thomas G: Furin at the cutting edge: from protein traffic to embryogenesis and disease. Nat Rev Mol Cell Biol 3: 753-766, 2002.

12. Nusse R and Varmus HE: Wnt genes. Cell 69: 1073-1087, 1992

13. McMahon AP, Gavin BJ, Parr B, et al: The Wnt family of cell signalling molecules in postimplantation development of the mouse. Ciba Found Symp 165: 199-218, 1992.

14. Polakis P: The many ways of Wnt in cancer. Curr Opin Genet Dev 17: 45-51, 2007

15. Smalley MJ and Dale TC: Wnt signalling in mammalian development and cancer. Cancer Metastasis Rev 18: 215-230, 1999.

16. Wang Y: Wnt/Planar cell polarity signaling: a new paradigm for cancer therapy. Mol Cancer Ther 8: 2103-2109, 2009.

17. Katoh M: WNT/PCP signaling pathway and human cancer (review). Oncol Rep 14: 1583-1588, 2005.

18. Hecht A, Vleminckx K, Stemmler MP, et al: The p300/CBP acetyltransferases function as transcriptional coactivators of beta-catenin in vertebrates. EMBO J 19: 1839-1850, 2000.

19. Takemaru KI and Moon RT: The transcriptional coactivator CBP interacts with beta-catenin to activate gene expression. J Cell Biol 149: 249-254, 2000.
20. Inagawa S, Itabashi M, Adachi S, et al: Expression and prognostic roles of beta-catenin in hepatocellular carcinoma: correlation with tumor progression and postoperative survival. Clin Cancer Res 8: 450-456, 2002.

21. Wong CM, Fan ST and Ng IO: beta-Catenin mutation and overexpression in hepatocellular carcinoma: clinicopathologic and prognostic significance. Cancer 92: 136-145, 2001.

22. Pulyaeva H, Bueno J, Polette M, Birembaut P, Sato H, Seiki M and Thompson EW: MT1-MMP correlates with MMP-2 activation potential seen after epithelial to mesenchymal transition in human breast carcinoma cells. Clin Exp Metastasis 15: 111-120, 1997.

23. Takahashi M, Tsunoda T, Seiki M, Nakamura Y and Furukawa Y: Identification of membrane-type matrix metalloproteinase-1 as a target of the beta-catenin/Tcf4 complex in human colorectal cancers. Oncogene 21: 5861-5867, 2002.

24. Kessenbrock K, Plaks V and Werb Z: Matrix metalloproteinases: regulators of the tumor microenvironment. Cell 141: 52-67, 2010.

25. Itoh Y and Seiki M: MT1-MMP: a potent modifier of pericellular microenvironment. J Cell Physiol 206: 1-8, 2006.

26. Kajita M, Itoh Y, Chiba T, Mori H, Okada A, Kinoh $\mathrm{H}$ and Seiki M: Membrane-type 1 matrix metalloproteinase cleaves CD44 and promotes cell migration. J Cell Biol 153: 893-904, 2001.

27. Deryugina EI, Ratnikov BI, Postnova TI, Rozanov DV and Strongin AY: Processing of integrin alpha(v) subunit by membrane type 1 matrix metalloproteinase stimulates migration of breast carcinoma cells on vitronectin and enhances tyrosine phosphorylation of focal adhesion kinase. J Biol Chem 277: 9749-9756, 2002

28. Overall CM: Molecular determinants of metalloproteinase substrate specificity: matrix metalloproteinase substrate binding domains, modules, and exosites. Mol Biotechnol 22: 51-86, 2002.

29. Harada T, Arii S, Mise M, Imamura T, Higashitsuji H, et al: Membrane-type matrix metalloproteinase-1(MT1-MMP) gene is overexpressed in highly invasive hepatocellular carcinomas. J Hepatol 28: 231-239, 1998.

30. Arii S, Mise M, Harada T, Furutani M, Ishigami S, Niwano M, et al: Overexpression of matrix metalloproteinase-9 gene in hepatocellular carcinoma with invasive potential. Hepatology 24: 316-322, 1996.

31. Nagase H, Visse R and Murphy G: Structure and function of matrix metalloproteinases and TIMPs. Cardiovasc Res 69: 562-573, 2006.

32. Egeblad $\mathrm{M}$ and Werb Z: New functions for the matrix metalloproteinases in cancer progression. Nat Rev Cancer 2: 161-174, 2002.

33. Kähäri VM and Saarialho-Kere U: Matrix metalloproteinases and their inhibitors in tumour growth and invasion. Ann Med 31: 34-45, 1999.

34. Sato H, Takino T, Okada Y, Cao J, Shinagaw A, Yamamoto E and Seiki M: A matrix metalloproteinase expressed on the surface of invasive tumour cells. Nature 370: 61-65, 1994

35. Sounni NE and Noel A: Membrane type-matrix metalloproteinases and tumor progression. Biochimie 87: 329-342, 2005.

36. Sato H, Takino $\mathrm{T}$ and Miyamori $\mathrm{H}$ : Roles of membrane-type matrix metalloproteinase-1 in tumor invasion and metastasis. Cancer Sci 96: 212-217, 2005.

37. Seiki M: Membrane-type 1 matrix metalloproteinase: a key enzyme for tumor invasion. Cancer Lett 194: 1-11, 2003.

38. Holmbeck K, Bianco P, Yamada S and Birkedal-Hansen H: MT1-MMP: a tethered collagenase. J Cell Physiol 200: 11-19, 2004. 